\title{
Intestinal schistosomiasis in Uganda at high altitude (>1400 m): malacological and epidemiological surveys on Mount Elgon and in Fort Portal crater lakes reveal extra preventive chemotherapy needs
}

\author{
Michelle C. Stanton ${ }^{1}$, Moses Adriko², Moses Arinaitwe $^{2}$, Alison Howell ${ }^{1}$, Juliet Davies ${ }^{1}$, Gillian Allison',
}

E. James LaCourse', Edridah Muheki ${ }^{2}$, Narcis B. Kabatereine ${ }^{2,3}$ and J. Russell Stothard ${ }^{1 *}$ (D)

\begin{abstract}
Background: Intestinal schistosomiasis is of public health importance in Uganda but communities living above $1400 \mathrm{~m}$ are not targeted for control as natural transmission is thought unlikely. To assess altitudinal boundaries and at-risk populations, conjoint malacological and epidemiological surveys were undertaken on Mount Elgon (1139 m-3937 m), in Fort Portal crater lakes and in the Rwenzori Mountains (1123 m-4050 m).

Methods: Seventy freshwater habitats [Mount Elgon (37), Fort Portal crater lakes (23), Rwenzori Mountains (8) and Lake Albert (2)] were inspected for Biomphalaria species. Water temperature, $\mathrm{pH}$ and conductivity were recorded. A parasitological examination of 756 schoolchildren [Mount Elgon (300), Fort Portal crater lakes (456)] by faecal microscopy of duplicate Kato-Katz smears from two consecutive stool samples was bolstered by antigen (urine-CCA dipstick) and antibody (SEA-ELISA) diagnostic assays.

Results: Biomphalaria spp. was found up to $1951 \mathrm{~m}$ on Mount Elgon and $1567 \mathrm{~m}$ in the Fort Portal crater lakes. Although no snail from Mount Elgon shed cercariae, molecular analysis judged $7.1 \%$ of snails sampled at altitudes above $1400 \mathrm{~m}$ as having DNA of Schistosoma mansoni; in Fort Portal crater lakes three snails shed schistosome cercariae. Prevalence of intestinal schistosomiasis as measured in schoolchildren by Kato-Katz (Mount Elgon $=5.3 \% \mathrm{v}$. Fort Portal crater lakes $=10.7 \%)$, CCA urine-dipsticks (18.3\% v. 34.4\%) and SEA-ELISA (42.3\% v. 63.7\%) showed negative associations with increasing altitude with some evidence of infection up to $2000 \mathrm{~m}$.
\end{abstract}

Conclusions: Contrary to expectations, these surveys clearly show that natural transmission of intestinal schistosomiasis occurs above $1400 \mathrm{~m}$, possibly extending up to $2000 \mathrm{~m}$. Using spatial epidemiological predictions, this now places some extra six million people at-risk, denoting an expansion of preventive chemotherapy needs in Uganda.

Keywords: School children, Schistosoma mansoni, Kato-Katz, CCA, SEA-ELISA, Biomphalaria

\footnotetext{
* Correspondence: russell.stothard@lstmed.ac.uk

${ }^{1}$ Department of Parasitology, Liverpool School of Tropical Medicine,

Pembroke Place, Liverpool L3 5QA, UK

Full list of author information is available at the end of the article
} 


\section{Multilingual abstracts}

Please see Additional file 1 for translations of the abstract into the six official working languages of the United Nations.

\section{Background}

Schistosomiasis is of considerable public health importance in sub-Saharan Africa [1]. Across the continent there are several national control programmes (NCPs) operating at various levels of scale-up, as guided by expectations set out within the WHO 2012-2020 Roadmap for neglected tropical diseases [2, 3]. In Uganda, since 2003 there has been an active NCP primarily concerned with the delivery of praziquantel to school-aged children $[4,5]$. Whilst each form of schistosomiasis can be found in Uganda, intestinal schistosomiasis, caused by Schistosoma mansoni (and transmitted by Biomphalaria spp.), is most common and widespread [6-8]. Just under 20 million people in 73 districts are estimated to be at-risk of infection [2]. The disease-endemic zone is most obvious within shoreline habitats of the Great Lakes and River Nile as well as in its vicinities nearby [3]. Outside of these however, large-scale ecological and epidemiological predictions have broadly set aside such areas as being unlikely to sustain natural transmission, for example, too cold (altitude $>1400 \mathrm{~m}$ ) or too arid (annual rainfall $<90 \mathrm{~cm}$ ) [9-12].

Alongside general surveillance and monitoring activities within the Ugandan NCP, an associated programme of operational and cross-country collaborative research has been undertaken $[13,14]$. This has explored the dynamics of environmental transmission in East Africa, especially in areas poorly sampled previously $[15,16]$. Schistosomesnail ecology has been addressed at either macro- and micro-epidemiological levels; many heterogeneities in biotic and (or) non-biotic factors have come to light [17-27]. In addition, more sensitive diagnostics tools have been introduced which go beyond routine parasitological sampling which has in turn increased abilities to better detect and differentiate schistosome infection(s) either in people [28, 29] or in snails [30-32]. Furthermore, with advances in geographical information systems and more affordable digital cartography [27, 33-36], new opportunities arise to review and refine earlier eco-epidemiological predictions. This includes targeted epidemiological surveys to 'ground-truth' assertions now better armed with new diagnostics.

This paper is an attempt to determine the risk of intestinal schistosomiasis transmission at higher altitudes in Uganda using data from two prospective malacological and epidemiological surveys conducted on Mount Elgon and in Fort Portal crater lakes. The surveys also make reference to Lake Albert and Rwenzori Mountains, assessing if natural transmission of intestinal schistosomiasis occurs at altitudes near to or exceeding $1400 \mathrm{~m}$.

\section{Methods}

Malacological surveys and laboratory investigations

At each freshwater habitat surveyed, global position system (GPS) coordinates, altitude and location photographs were taken with an Oregon 650 receiver (Garmin, Olathe, Kansas, USA). Water temperature $\left({ }^{\circ} \mathrm{C}\right)$, $\mathrm{pH}$ and conductivity $(\mu \mathrm{S})$ were recorded with a HI98129 Pocket EC/TDS and $\mathrm{pH}$ Tester (Hanna Instruments Ltd, Leighton Buzzard, Bedfordshire, UK). Two snail collectors searched for Biomphalaria spp. by hand and with metal scoops, for over $20 \mathrm{~min}$ at each site. All collected snails were counted then transferred into plastic cups containing mineral water, exposed to light for two hours, then checked for shedding cercariae under the dissecting microscope. Thirty seven sites (1139 m$3937 \mathrm{~m}$ ) were surveyed in June 2011 in the Mount Elgon area, to include areas located close to sampled schools (see below). Within the Fort Portal crater lakes, 23 sites (1123 m-1567 m) were surveyed in June 2012, including a selection of those previously visited by Rubaihayo et al. in 2006 [37], with sampling taking place in areas of the lakes known to be used by local communities for fishing and domestic activities. Eight further higher altitude sites were surveyed by foot in the Rwenzori Mountains $(1620 \mathrm{~m}-4050 \mathrm{~m})$, plus an additional two by car on the southern shore of Lake Albert (616 m and $624 \mathrm{~m}$ ) as low altitude reference.

Biomphalaria spp. collected from Mount Elgon was placed in absolute ethanol, transferred to the UK and genomic DNA was extracted according to standard protocols. A total of 118 snails (33 from $<1400 \mathrm{~m}$ and 85 from $>1400 \mathrm{~m}$ ) were then screened by polymerase chain reaction (PCR) for schistosome DNA following protocols described by Kane et al. [32] using schistosome-specific primers, RAKqIGSF (5' AAA GTC GGA AAA ATG AAA 3') and RAKqIGSR (5' TAT GAA TGA AAT CGG TTA 3') for a sub-region of the nuclear ribosomal intergenic spacer [32]. Amplicons were separated by 1.5\% agarose gel electrophoresis and stained with ethidium bromide. A snail was judged to be infected with S. mansoni if a 300 base pairs fragment that could also be digested with the restriction enzyme Acc1 was observed [32].

\section{Epidemiological surveys and diagnostic assays}

The GPS coordinates and elevation of each sampled school were recorded. Within the Mount Elgon area, six universal primary education (UPE) schools were included: 3 at higher altitudes $(1856 \mathrm{~m}-2072 \mathrm{~m})$ and three at lower altitudes (1150 m-1268 m). Schools were sampled randomly within two elevation strata $(<1500 \mathrm{~m}$ and $>1500 \mathrm{~m}$ ). Within each school, 50 children were randomly selected (25 boys, 25 girls) from classes Primary 5 - Primary 7 (age range of 10-13 years). Within the Fort Portal Crater Lakes area, 14 UPE schools (1165 m-1526 m) were 
selected, six of which had been surveyed previously by Rubaihayo et al. in 2006 [37]. The additional schools were selected purposively such that they covered a range of altitudes and were close to a crater lake. An additional school was sampled close to the southern shores of Lake Albert $(621 \mathrm{~m})$, an area where transmission is known to be high, as a comparison. Within each school, 30 children were examined. No school was sampled in the Rwenzori Mountains as the survey took place within the Rwenzori National Park.

Specimen collection and diagnostic testing took place over a two day period with methods described previously [38]. Urine, stool and finger-prick blood samples were taken on the first day, with an additional stool sample obtained on the second day. Faecal microscopy involved inspection of duplicate thick Kato-Katz smears from each faecal sample with egg counting at $\times 100$ magnification. A urine-CCA dipstick test (Rapid Medical Diagnostics, Pretoria, South Africa) was used to detect intestinal schistosomiasis and $3 \mu \mathrm{l}$ of harvested sera was used for detection of antibodies against soluble egg antigen (SEA-ELISA) with a commercially available kit (IVD Inc.; Carlsbad, USA). All sampled children were treated on site with praziquantel $(40 \mathrm{mg} / \mathrm{kg}$, Cipla, Mumbai, India) and albendazole (400 mg, GSK, Hertford, Hertfordshire, UK) irrespective of infection status.

\section{Spatial and statistical analyses}

The relationship between altitude and the survey results was explored through the production of maps and scatter plots using the geographical information software QGIS (version 2.18.1) [39] and the statistical software R (version 3.3.1) [40]. In addition to mapping the geographical coordinates of the survey sites, elevation data at a $90 \mathrm{~m}$ resolution was obtained from NASA's Shuttle Radar Topography Mission (SRTM) [41] and displayed using elevation bands of less than $1000 \mathrm{~m}, 1000$ $1200 \mathrm{~m}, 1200-1400 \mathrm{~m}, 1400-1600 \mathrm{~m}, 1600-1800 \mathrm{~m}$, 1800-2000 m and greater than $2000 \mathrm{~m}$ for the whole of Uganda. With regards to the malacological survey data, in addition to plotting elevation against number of Biomphalaria spp. caught at each site, plots of water temperature $\left({ }^{\circ} \mathrm{C}\right), \mathrm{pH}$ and conductivity against elevation were produced in order to explore further this relationship.

Plots of school prevalence using all three diagnostic methods were produced and a relationship between the pooled prevalence results using each of the three diagnostic methods and elevation was assessed by fitting a logistic regression model to the data. The goodness of fit of these models was assessed by calculating the deviance statistic [42]. In order to explore the currently available information on high altitude schistosomiasis transmission excluding the surveys presented in this paper, georeferenced schistosomiasis prevalence data obtained primarily using Kato-Katz were downloaded from the Global Atlas of Helminth Infections (GAHI) website [43]. This database is a collation of prevalence data from multiple sources including the published literature and the national NTD control programme [33, 44, 45]. The elevation of each georeferenced point was extracted from the $90 \mathrm{~m}$ resolution SRTM data, and summaries of surveys, including the number undertaken and the reported prevalence ranges by elevation bands, were reported.

The altitude of each georeferenced point was extracted from the $90 \mathrm{~m}$ resolution SRTM data, and summaries of surveys, including the number undertaken and the reported prevalence ranges by elevation bands, were reported. Finally, using $100 \mathrm{~m}$ gridded population data for 2015 obtained from WorldPop (http://www.worldpop.org.uk/) the number of people living within elevation bands of less than $1400 \mathrm{~m}, 1400-2000 \mathrm{~m}$ and greater than $2000 \mathrm{~m}$ was calculated in order to obtain a crude estimate of the number of people at-risk.

\section{Results \\ Malacological findings}

Figure 1 presents an overview of the locations of the snail sampling sites across Uganda, with all data in Additional file 2: Table S1. Within the Mount Elgon area, Biomphalaria spp. were found at $30 \%(11 / 37)$ of sampled sites at altitudes as high as $1951 \mathrm{~m}$ whereas in the Fort Portal crater lakes were found 92\% (21/23) of sampled sites, at a maximum altitude of $1567 \mathrm{~m}$. No Biomphalaria spp. were found in the Rwenzori Mountains. Biomphalaria spp. were found in one of the two low altitude sites on Lake Albert. Scatter plots of number of Biomphalaria spp. against altitude (Fig. 2) indicated that no Biomphalaria spp. were found above $2000 \mathrm{~m}$. There was no discernible pattern in the number of snails and altitude below this value. Plots of water temperature, $\mathrm{pH}$ and conductivity against altitude, indicate that whilst there appears to be a negative linear relationship between temperature and altitude, see Fig. 3, the water in Mount Elgon has a lower $\mathrm{pH}($ median $=8.3)$ than that of Fort Portal crater lakes area (median $=11.3$ ) and the Rwenzori Mountains (median =9.5). There is no clear trend between $\mathrm{pH}$ and altitude or Biomphalaria spp.. A negative association of conductivity with increasing altitude was observed, with the lowest values $(<100 \mu \mathrm{S})$ being found at sites at very high altitudes $(>3000 \mathrm{~m})$.

A total of 264 Biomphalaria spp. collected from Mount Elgon were observed for shedding cercariae under natural conditions on at least one occasion. While non-human cercariae were seen, no snail shed schistosome cercariae. Upon PCR analysis conducted in the UK, 16 snails from a total of 33 screened from below $1400 \mathrm{~m}$ and six snails from a total of 85 screened from above 1400 m were judged infected with $S$. mansoni with 

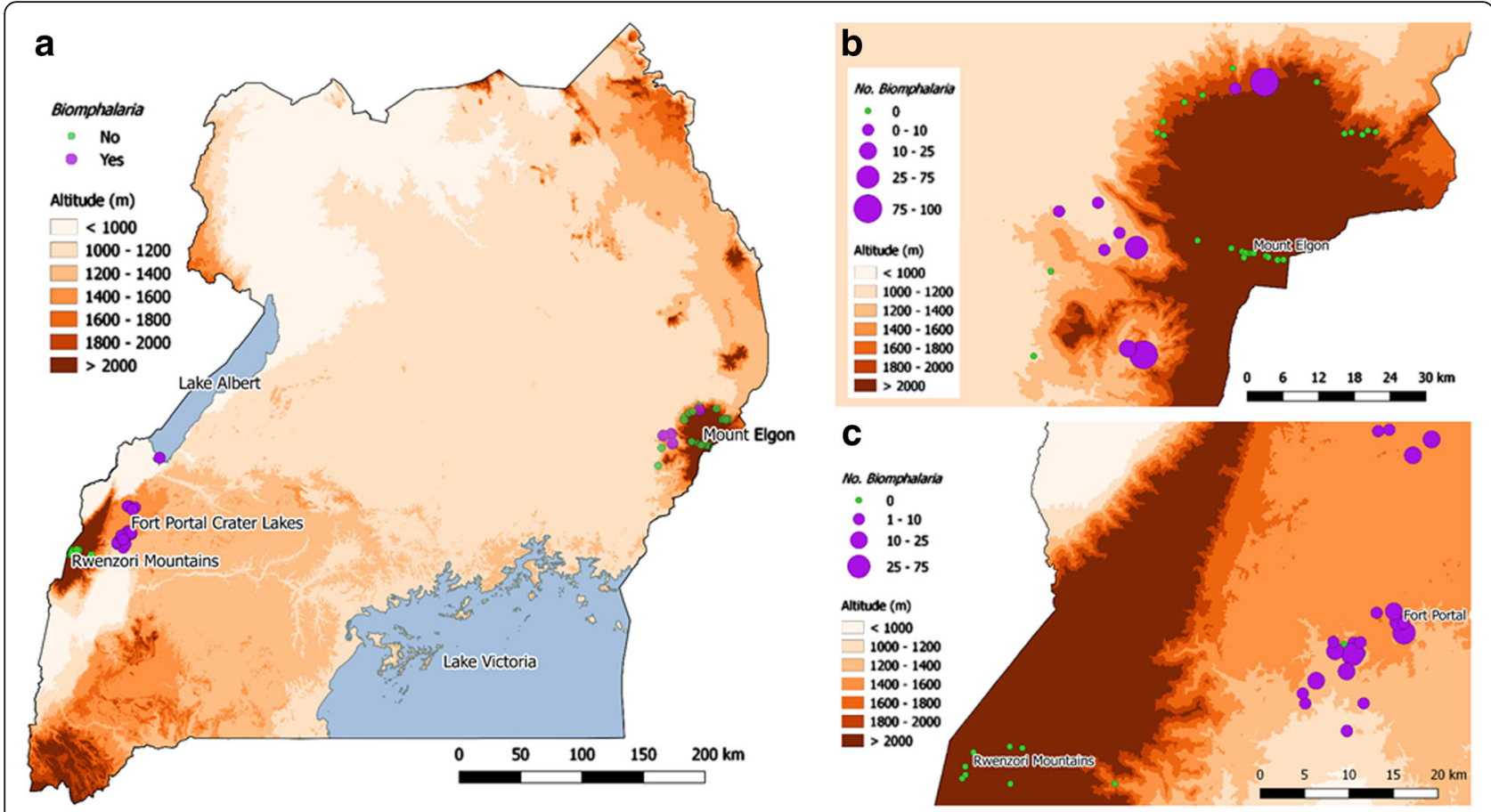

Fig. 1 Outline maps of Uganda showing altitude and malacological sampling points. a Country overview of Mount Elgon (East) and Fort Portal crater lakes and Rwenzori Mountains (West); sample sites where Biomphalaria spp. were found are indicted purple whereas green denotes no Biomphalaria spp. encountered. b Mount Elgon area c Fort Portal Crater Lakes and Rwenzori Mountains and area

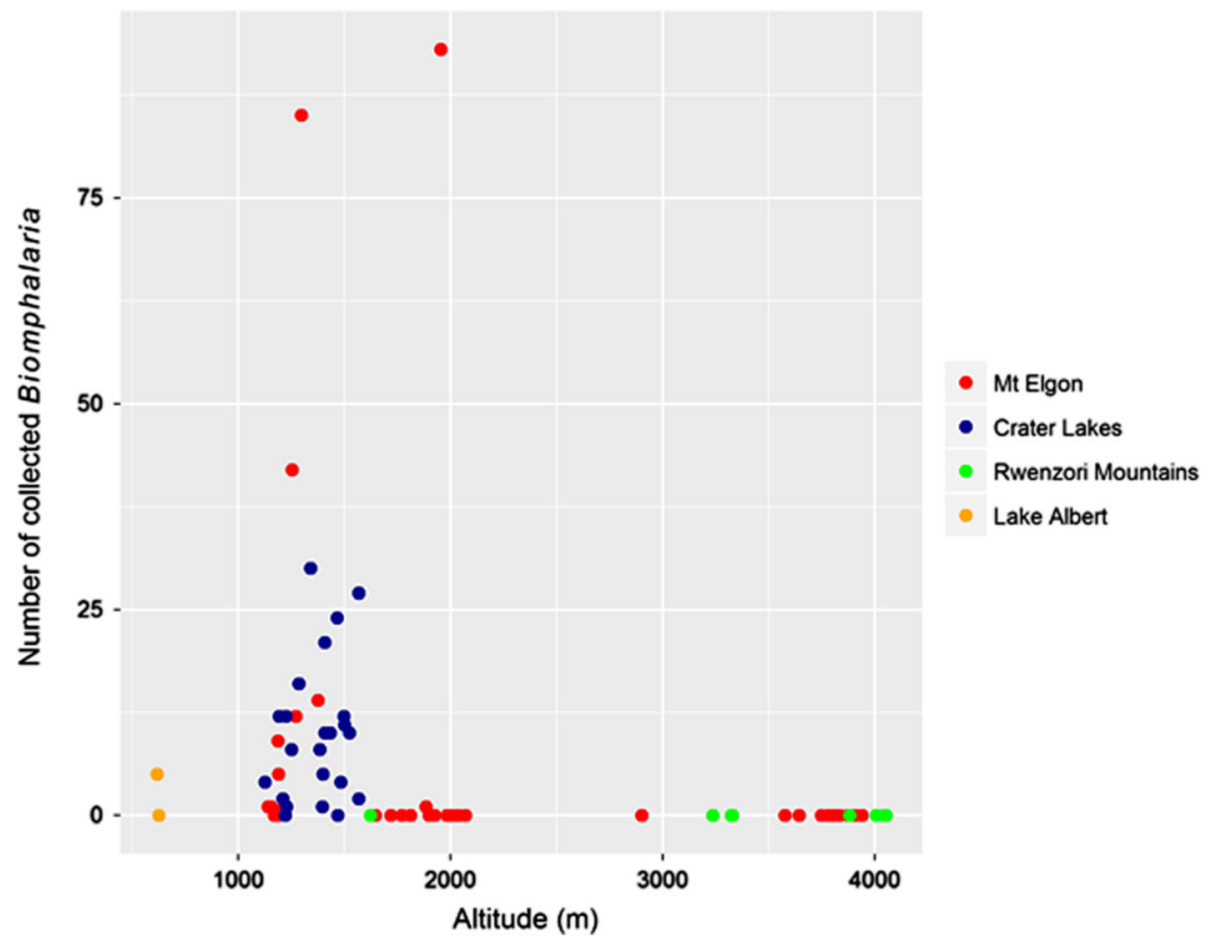

Fig. 2 Scatterplot of number of Biomphalaria spp. collected at each site against altitude 


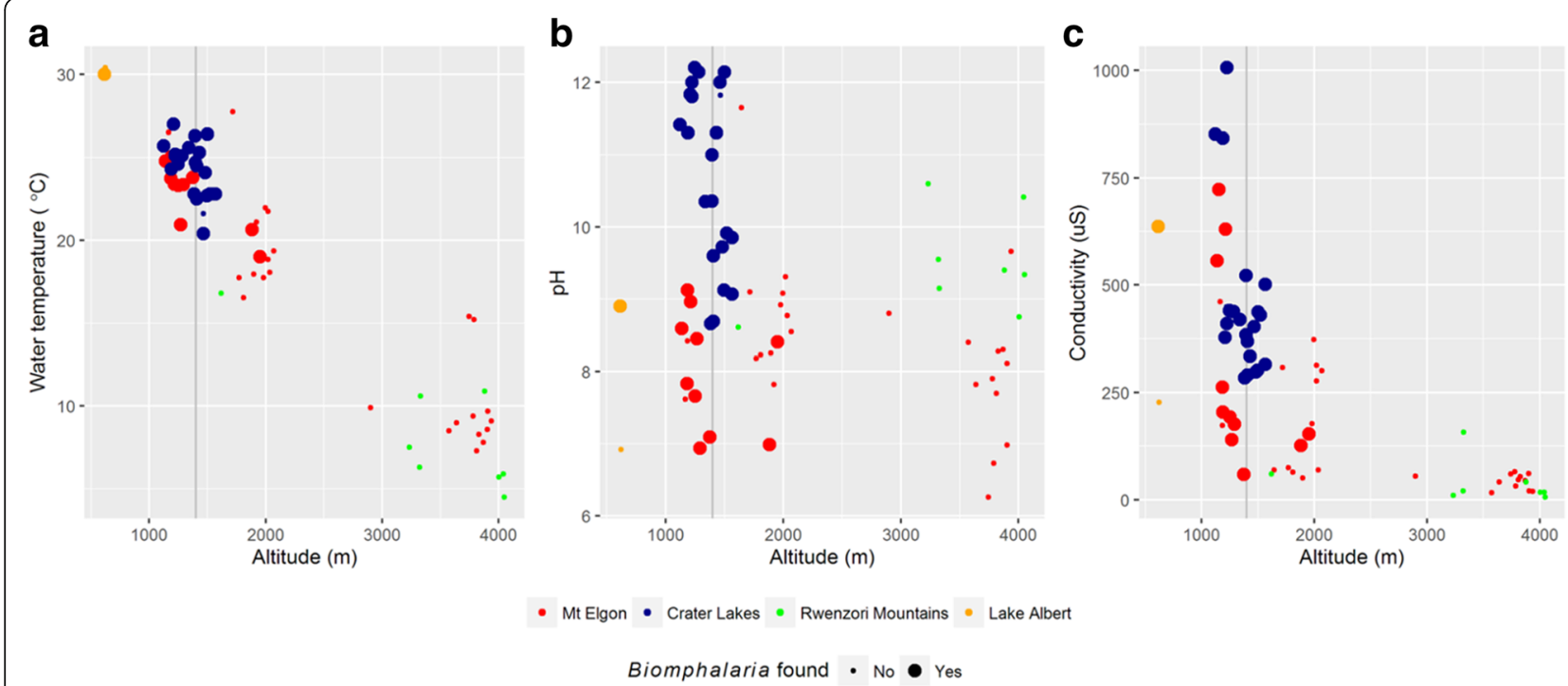

Fig. 3 Scatterplot of water temperature (a), pH (b) and conductivity (c) at each snail site (Mount Elgon = red, Crater Lakes = blue, Rwenzoru Mountains = green, Lake Albert = orange) against altitude for all survey areas. Large circles represent sites were at least one Biomphalaria spp. was found

a prevalence of 48.5 and $7.1 \%$, respectively. In total, 235 Biomphalaria spp. collected from Fort Portal crater lakes were observed for shedding cercariae, with three snails from Nyinambuga and Lyantonde, two independent crater lakes, patently shedding schistosome cercariae.

\section{Epidemiological findings}

Table 1 presents the overall prevalence of $S$. mansoni within schools sampled from Mount Elgon, Fort Portal crater lakes and Lake Albert as measured by Kato-Katz, CCA and SEA-ELISA. Prevalence by SEA-ELISA testing in the Mount Elgon and Fort Portal crater lakes areas are shown in Fig. 4, with Fig. 5 depicting school-level prevalence against altitude for each of the three diagnostic methods. Prevalence as obtained with each diagnostic decreases with increasing altitude (SEA-ELISA: Lake Albert $=100 \%$, Fort Portal crater lakes $=60.4 \%$, Mount Elgon $=42.3 \%)$. Individual school data can be found in Additional file 3: Table S2. According to SEA-ELISA testing there is strong evidence of infection at higher altitudes, such that a prevalence of $26.7 \%$ (40/150) was detected in the three most elevated schools (1856-2072 m), falling to $10.0 \%(15 / 150)$ and $1.3 \%$ $(2 / 150)$ using CCA and Kato-Katz, respectively. Of note, is that these schools are within reasonable proximity (approximately $10 \mathrm{~km}$ ) to a location where numerous Biomphalaria spp. were found, Fig. 4.

The logistic regression model fitted to the prevalence data obtained using each of the three diagnostic methods, with elevation as the only risk factor, are presented in Table 2. The resulting odds ratios were 0.9977 (95\% CI: 0.9947-0.9966), $0.9974 \quad$ (95\% CI: $0.9967-$ $0.9980)$ and 0.9957 (95\% CI: 0.9947-0.9966) for SEAELISA, CCA and Kato-Katz respectively. Thus, at the $1400 \mathrm{~m}$ threshold the fitted models predict prevalence values of $59.0 \%$ (95\% CI: $55.2 \%-62.7 \%$ ), $29.8 \%$ (95\% CI: 26.4-33.4\%), 7.8\% (95\% CI: 5.9-10.2\%) for ELISA, CCA and Kato-Katz, respectively. It should be noted however that these models had a poor goodness of fit $(P<0.05)$.

Of the 671 geolocated survey sites in the GAHI database (excluding the seven surveys whose coordinates were outside of the country boundary), 93.7\% $(629 / 671)$ were below an altitude of $1400 \mathrm{~m}$. Of the remaining 42 surveys, 17 were within the $1400-$ $1600 \mathrm{~m}$ range, five were within $1600 \mathrm{~m}-1800 \mathrm{~m}$ and 14 were within $1800 \mathrm{~m}-2000 \mathrm{~m}$. The majority of surveys $(94.3 \%, 633 / 671)$ used single Kato-Katz faecal smears to estimate prevalence of $S$. mansoni with egg-patent prevalence ranging from 0.0 to $57.0 \%$ (1400 m-1600 m), 0.0-1.7\% (1600-1800 m) and 0.0\%-

Table 1 Summary of school-level schistosomiasis prevalence by area and diagnostic method

\begin{tabular}{|c|c|c|c|c|c|c|c|c|}
\hline & \multirow[t]{2}{*}{ Elevation } & \multirow[t]{2}{*}{$N$} & \multicolumn{2}{|l|}{ SEA-ELISA } & \multicolumn{2}{|l|}{ CCA } & \multicolumn{2}{|l|}{ Kato-Katz } \\
\hline & & & Prevalence (\%) & $95 \% \mathrm{Cl}$ & Prevalence (\%) & $95 \% \mathrm{Cl}$ & Prevalence (\%) & $95 \% \mathrm{Cl}$ \\
\hline Mount Elgon & 1150-2072 & 300 & 42.3 & $36.7-48.2$ & 18.3 & $14.2-23.3$ & 5.3 & $3.2-8.7$ \\
\hline Crater Lakes & $1165-1526$ & 420 & 63.7 & 58.9-68.3 & 34.4 & $29.9-39.1$ & 10.7 & $8.0-14.1$ \\
\hline Lake Albert & 621 & 30 & 100.0 & $87.4-100.0$ & 97.1 & 82.9-99.8 & 70.1 & $52.3-84.3$ \\
\hline
\end{tabular}


a
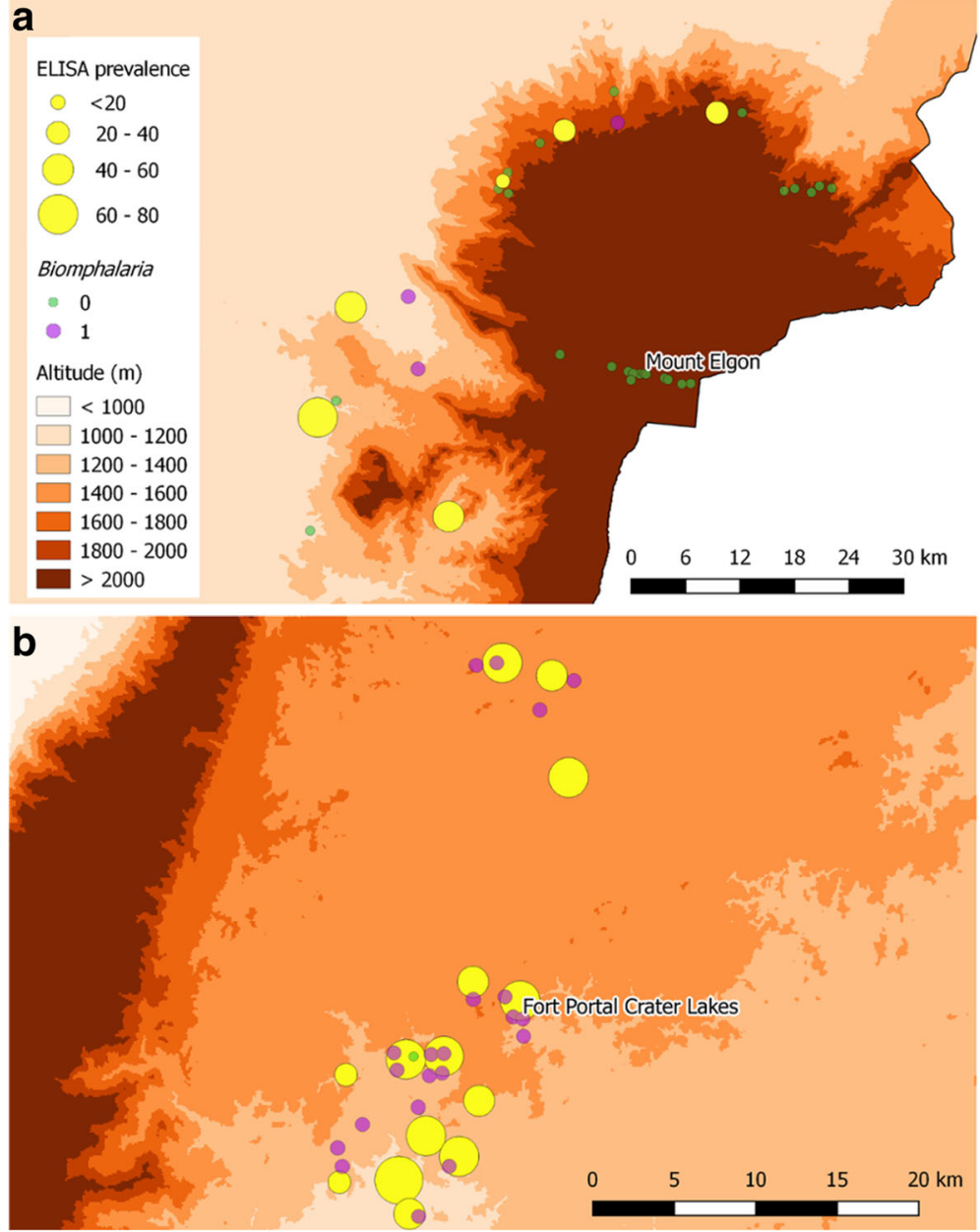

Fig. 4 Schematic maps of prevalence of intestinal schistosomiasis at each surveyed schools according to SEA-ELISA depicted as yellow coloured circles in the Mount Elgon (a) and Fort Portal crater lakes (b) areas. Snail sampling sites are also depicted as purple (Biomphalaria present) and green (Biomphalaria spp. absent) coloured circles

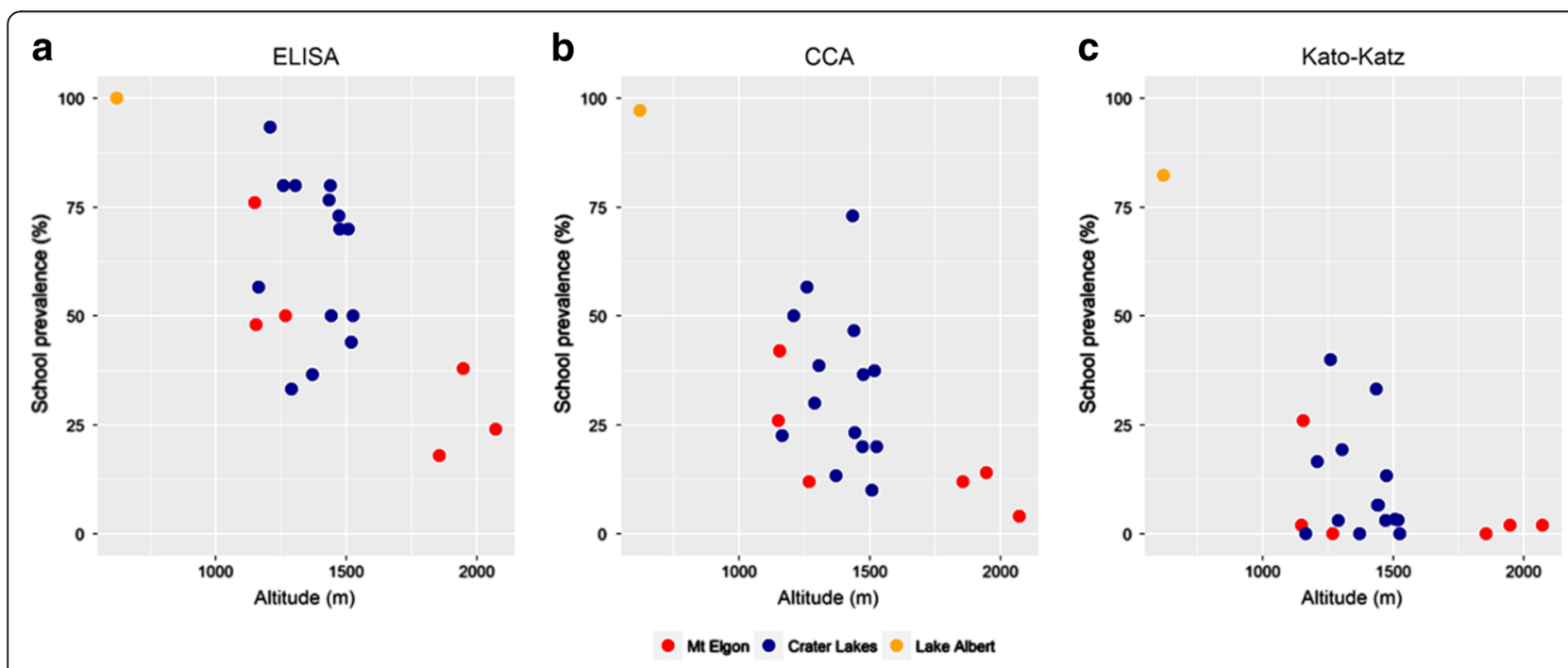

Fig. $\mathbf{5}$ Scatter plots of prevalence of intestinal schistosomiasis by school according to SEA-ELISA prevalence (a), CCA urine-dipstick (b) and Kato-Katz (c) show a negative relationship with increasing altitude 
Table 2 Logistic regression results for school-level schistosomiasis prevalence with elevation as a risk factor by each diagnostic method

\begin{tabular}{|c|c|c|c|c|c|c|c|}
\hline & & \multicolumn{2}{|l|}{ SEA-ELISA } & \multicolumn{2}{|l|}{ CCA } & \multicolumn{2}{|l|}{ Kato-Katz } \\
\hline & & Coefficient & $95 \% \mathrm{Cl}$ & Coefficient & $95 \% \mathrm{Cl}$ & Coefficient & $95 \% \mathrm{Cl}$ \\
\hline \multirow[t]{2}{*}{$\log O R$} & Intercept & 3.49 & $2.74,4.28$ & 2.74 & $1.92,3.61$ & 3.52 & $2.38,4.77$ \\
\hline & Elevation & -0.0022 & $-0.0028,-0.0017$ & -0.0026 & $-0.0032,-0.0020$ & -0.0043 & $-0.0053,-0.0034$ \\
\hline \multirow[t]{2}{*}{$O R$} & Intercept & 32.81 & $15.43,72.21$ & 15.44 & $6.81,36.88$ & 33.75 & $10.77,117.38$ \\
\hline & Elevation & 0.9978 & $0.9972,0.9983$ & 0.9974 & $0.9967,0.9980$ & 0.9957 & $0.9947,0.9966$ \\
\hline
\end{tabular}

$3.4 \%(1800-2000 \mathrm{~m})$. No cases were found at any sites at an altitude greater than $2000 \mathrm{~m}$.

\section{Estimating the at-risk population}

Using the gridded population estimates from WorldPop $(100 \mathrm{~m})$ and SRTM elevation $(90 \mathrm{~m})$, of the 39.2 million people living in Uganda, 82.8\% (32.5 million) of people live at altitudes below $1400 \mathrm{~m}$. Of the remainder, $15.4 \%$ (6 M) live within an altitude range of $1400 \mathrm{~m}-2000 \mathrm{~m}$ and the remaining $1.8 \%$ (0.7 million) live above $2000 \mathrm{~m}$.

\section{Discussion}

The analysis presented in this paper demonstrates the potential for intestinal schistosomiasis transmission at altitudes greater than $1400 \mathrm{~m}$. This was clearly demonstrated both by the presence of disease and by the presence of intermediate snail hosts in Mount Elgon and Fort Portal crater lakes, respectively. The prevalence of disease at these higher altitudes should not be overlooked, and as such should be considered for inclusion in the national control programme.

For natural transmission of intestinal schistosomiasis to occur, several critical aspects within the lifecycle of $S$. mansoni need to be fulfilled [22, 34, 46, 47]. Foremost perhaps, is the presence of permissive populations of Biomphalaria spp., alongside sufficient environmental opportunity for larval stages of the schistosome to encounter and successfully develop within both definitive and intermediate hosts. As might be expected, there is an optimal range of temperatures operating across these processes both in time and space which may facilitate or, where thermal boundaries are exceeded by being too cold or too hot, stall natural transmission [22]. Hence there is ample reason and often sufficient ecological evidence to attempt to predict where transmission is or is not possible. There are, however, well-known conceptual problems broadly grouped as issues of geographical scale $[27,35,36,48]$. In terms of public health, the implication of this can be profound for it may under-estimate or over-estimate the preventive chemotherapy needs of people living within areas predicted or proven to be atrisk $[9,16,49]$. Where resources permit, it is therefore sensible to have iterative cycles that progressively refine any prediction(s) such that subsequent validations are undertaken to 'ground-truth' any newly envisaged scenario.

The first formal attempt to describe the distribution of Biomphalaria spp. in Uganda was by Georg MandahlBarth in his 1954 monograph entitled "The freshwater mollusks of Uganda and adjacent territories" [50]. His attention focused most on Biomphalaria spp. from the great lakes and in lowland areas but mention was made of the crater lake fauna south of Fort Portal where he considered Biomphalaria adowensis adowensis (Bourguignat, 1879) to occur. Realising that his knowledge of the distribution and ecology of many species was scant, he provided only a broad overview but observed that Biomphalaria $r$ ppellii (Dunker, 1848) was found in highland areas in the South-West of the country within Lakes Mutanda $(1800 \mathrm{~m})$ and Bunyonyi (1962 m) [50]. Since then many of the older species names of Biomphalaria have been synonymised as the genus has been downwardly revised to represent some 12 species in total [51]. Most importantly all currently named species have some natural or experimental compatibility with $S$. mansoni hence the presence of Biomphalaria spp. alone is sufficient to raise suspicion of local transmission potential $[17,51]$. Clearly from the information provided here, Biomphalaria spp. has been proven to be found at altitudes very close to $2000 \mathrm{~m}$ on Mount Elgon and with reference to Lake Bunyonyi was first reported in the 1930s [50] and is present today.

Even with the introduction of molecular DNA typing methods for species delineation, it remains difficult to describe and record precisely the distribution of each species of Biomphalaria in Uganda [52]. A good example is the status of populations in Lake Victoria although there have been successful attempts to map, describe and predict general distributions throughout the lake [15, 24-26, 38]. In terms of assessing transmission, recourse to a combination of traditional methods to inspect snails for evidence of infection, by cercarial shedding for example, alongside new DNA assays to detect schistosomes in snails is a powerful way to assess transmission in nature $[32,38]$. With the observation of schistosome cercariae, it is apparent that active transmission was caught in action and was occurring during the survey of the Fort Portal crater lakes. It is perhaps 
unsurprising that the previous survey of Rubaihayo et al. found egg-patent prevalence of $27.8 \%$ around the crater lakes within the altitudinal range of $1487 \mathrm{~m}-1682 \mathrm{~m}$ [37]. There are also several recent reports of travellers contracting intestinal schistosomiasis locally from these crater lakes [53]. While shedding cercariae were not observed in the Mount Elgon survey, 7.1\% of examined snails did have evidence of schistosome DNA which at the very least, demonstrates either recent encounters with schistosome miracidia or that snails were incubating sporocysts within the pre-patent period before cercariogenesis [54]. With hindsight our malacological surveys should have inspected a sub-sample of snails by crushing to visualise the presence of sporocyts and bolster this with recourse to real-time PCR approaches which can better quantify levels of schistosome DNA than traditional PCR methods using gel electrophoresis. With better quantification of DNA it should be possible to set a detection threshold which if exceeded, differentiates miracidial-contamination from cercarialemergence events.

With the introduction of more sensitive diagnostics for intestinal schistosomiasis in people which clearly evidence the limitations of Kato-Katz, it is not surprising that a greater number of infections were encountered [29]. Figs. 4 and 5 demonstrate that while egg-patent prevalence was less than $5.0 \%$, using SEA-ELISA or CCA the prevalence would fall somewhere between 5.0 and $37.5 \%$ in UPE schools above $1400 \mathrm{~m}$. It is therefore safe to assume that rather than schistosomiasis being absent, it only appears absent due to the use of insensitive diagnostic tests. Table 2 shows that while there is a negative association with altitude there is a significant amount of infection between 1400 and $1600 \mathrm{~m}$, with a likely absolute boundary exceeding $2000 \mathrm{~m}$, although it should be noted however that these logistic regression models had a poor goodness of fit $(P<0.05)$ possibly due to the lack of additional important risk factors in the model or the small sample size. More data are therefore needed to explore this finding further. As an example, a prior survey for intestinal schistosomiasis at Hamukaaka (also known as Amasiko) village was undertaken on the shoreline of Lake Buynonyi $(\sim 1960 \mathrm{~m})$ in 2006 and tested both pre-school children $(n=26)$ and their mothers $(n=29)$ by finger prick SEA-ELISA, urine-CCA dipsticks and stool concentration methods. Although Biomphalaria spp. could be found locally, there was no evidence of schistosome infection in children or in adults [55].

For those people living above $1400 \mathrm{~m}$ who are eggnegative by Kato-Katz but are positive by SEA-ELISA or urine-CCA test should have access to praziquantel treatment. Moreover, the significance of 'asymptomatic' schistosomiasis has been debated, concluding that there is a tangible benefit to treating those who have any evidence of infection [56]. Using available data on population density it is safe to assume that some 6.7 million people live within inhabited areas above $1400 \mathrm{~m}$ and that a sizeable fraction, perhaps a quarter to a half, will likely have intestinal schistosomiasis. However, these people have not yet been reached with treatment. Rather than set aside these areas for control, there is now an imperative for expanded access to preventive chemotherapy to be undertaken. This is especially true if control ultimately aims to eliminate morbidity and transmission, otherwise intestinal schistosomiasis could continue on within such high altitude refugia.

\section{Conclusions}

These conjoint parasitological and malacological surveys undertaken on Mount Elgon and in the Fort Portal Crater Lakes clearly show that natural transmission of $S$. mansoni occurs at altitudes above $1400 \mathrm{~m}$, with a putative upper boundary of $2000 \mathrm{~m}$, and reveals additional preventive chemotherapy needs. In future, collected snails should also be examined for the presence of developing sporocysts by microscopy as well as implement real-time PCR techniques to better quantify levels of schistosome DNA snails with pre-patent infection(s). In these highlands, there is an appreciable burden of intestinal schistosomiasis in school children attending UPE schools. Using spatial epidemiological predictions, this now places some extra six million Ugandans at-risk of disease and calls for a much needed expansion of preventive chemotherapy by the Ugandan NCP in these highland areas. This will not only provide more equitable distribution of praziquantel treatment but also prevent schistosomes from making transmission refugia at higher altitude.

\section{Additional files}

Additional file 1: Multilingual abstracts in the six official working languages of the United Nations. (PDF 809 kb)

Additional file 2: Table S1. Malacological data. (XLSX 16 kb)

Additional file 3: Table S2. Epidemiological data. (CSV 1 kb)

\section{Abbreviations \\ CCA: Circulating cathodic antigen; GAHI: Global atlas of helminth infections; NCP: National control programme; PCR: Polymerase chain reaction; SEA-ELISA: Soluble egg antigen-enzyme linked immunosorbent assay; SRTM: Shuttle radar topography mission; UPE: Universal primary education}

\section{Acknowledgements}

We are grateful to the help of the VCD field team and local VCD officers in Kabarole and Kabale, in particular Clouds Philbert who has helped us since 2006. We thank the GSA and Professor X Zhou for organising and facilitating this special issue of Infectious Diseases of Poverty. 


\section{Funding}

Members of LSTM within the COUNTDOWN consortium received funding from the Research and Evidence Division, Department for International Development, UK. MCS is directly funded by the Medical Research Council, UK.

\section{Availability of data and materials}

Additional file 2: Table S1 and Additional file 3: Table S2.

\section{Authors' contributions}

MCS, EH, NBK \& JRS conceived study design and conducted fieldwork with MAd, Mar, EJLa, JD, GA and AH. All authors contributed to writing the manuscript and gave approval of its final form.

\section{Competing interests}

The authors declare that they have no competing interests.

\section{Consent for publication}

All authors provided consent for publication.

\section{Ethics approval and consent to participate}

The study was approved by the LSTM and Uganda Council for Science and Technology.

\section{Author details}

'Department of Parasitology, Liverpool School of Tropical Medicine, Pembroke Place, Liverpool L3 5QA, UK. ² Vector Control Division, Ministry of Health, KampalaP.O. Box 1661Uganda. ${ }^{3}$ Schistosomiasis Control Initiative, Imperial College London, London W2 1PG, UK.

\section{Received: 17 November 2016 Accepted: 19 January 2017}

\section{Published online: 06 February 2017}

\section{References}

1. Colley DG, Bustinduy AL, Secor WE, King CH, Vos T, Flaxman A, et al. Human schistosomiasis. Lancet. 2014;383:2253-64.

2. World Health Organization. Schistosomiasis: progress report 2001-2011, strategic plan 2012-2020. Geneva: WHO; 2013. http://www.who.int/ neglected_diseases/resources/9789241503174/en/.

3. World Health Organization. Accelerating work to overcome the global impact of neglected tropical diseases: A roadmap for implementation. 2012.

4. Loewenberg S. Uganda's struggle with schistosomiasis. Lancet (London, England). 2014;383:1707-8.

5. Fenwick A, Webster JP, Bosque-Oliva E, Blair L, Fleming FM, Zhang Y, et al. The Schistosomiasis Control Initiative (SCl): rationale, development and implementation from 2002-2008. Parasitology. 2009:136:1719.

6. Kabatereine NB, Brooker S, Tukahebwa EM, Kazibwe F, Onapa AW. Epidemiology and geography of Schistosoma mansoni in Uganda: implications for planning control. Trop Med Int Health. 2004;9:372-80.

7. Kabatereine NB, Fleming FM, Nyandindi U, Mwanza JCL, Blair L. The control of schistosomiasis and soil-transmitted helminths in East Africa. Trends Parasitol. 2006;22:332-9.

8. Kabatereine NB, Brooker S, Koukounari A, Kazibwe F, Tukahebwa EM, Fleming FM, et al. Impact of a national helminth control programme on infection and morbidity in Ugandan schoolchildren. Bull World Health Organ. 2007;85:91-9.

9. Clements ACA, Deville M-A, Ndayishimiye O, Brooker S, Fenwick A. Spatial co-distribution of neglected tropical diseases in the East African Great Lakes region: revisiting the justification for integrated control. Trop Med Int Health. 2010;15:198-207.

10. Stensgaard AS, Jørgensen A, Kabatereine NB, Rahbek C, Kristensen TK. Modeling freshwater snail habitat suitability and areas of potential snail-borne disease transmission in Uganda. Geospat Health. 2006;1:93.

11. Walz Y, Wegmann M, Dech S, Vounatsou P, Poda J-N, N'Goran EK, et al. Modeling and validation of environmental suitability for schistosomiasis transmission using remote sensing. PLoS Negl Trop Dis. 2015;9:e0004217.

12. Clements ACA, Moyeed R, Brooker S. Bayesian geostatistical prediction of the intensity of infection with Schistosoma mansoni in East Africa. Parasitology. 2006;133:711-9.

13. Dunne DW, Vennervald BJ, Booth $M$, Joseph S, Fitzsimmons CM, Cahen P, et al. Applied and basic research on the epidemiology, morbidity, and immunology of schistosomiasis in fishing communities on Lake Albert, Uganda. Trans R Soc Trop Med Hyg. 2006;100:216-23.

14. Utzinger J, Brattig NW, Kristensen TK. Schistosomiasis research in Africa: how the CONTRAST alliance made it happen. Acta Trop. 2013;128:182-95.

15. Standley CJ, Adriko M, Arinaitwe M, Atuhaire A, Kazibwe F, Fenwick A, et al. Epidemiology and control of intestinal schistosomiasis on the Sesse Islands, Uganda: integrating malacology and parasitology to tailor local treatment recommendations. Parasit Vectors. 2010;3:64

16. Standley CJ, Stothard JR. Towards defining appropriate strategies for targeted NTD control. Trop Med Int Health. 2010;15:772-3.

17. Adriko M, Standley CJ, Tinkitina B, Mwesigwa G, Kristensen TK, Stothard JR et al. Compatibility of Ugandan Schistosoma mansoni isolates with Biomphalaria snail species from Lake Albert and Lake Victoria. Acta Trop. 2013;128:303-8.

18. Betson M, Sousa-Figueiredo JC, Kabatereine NB, Stothard JR. New insights into the molecular epidemiology and population genetics of Schistosoma mansoni in Ugandan pre-school children and mothers. PLoS Negl Trop Dis. 2013;7:e2561.

19. Kazibwe F, Makanga B, Rubaire-Akiiki C, Ouma J, Kariuki C, Kabatereine NB, et al. Ecology of Biomphalaria (Gastropoda: Planorbidae) in Lake Albert, Western Uganda: snail distributions, infection with schistosomes and temporal associations with environmental dynamics. Hydrobiologia. 2006; 568:433-44.

20. Kazibwe F, Makanga B, Rubaire-Akiiki C, Ouma J, Kariuki C, Kabatereine NB, et al. Transmission studies of intestinal schistosomiasis in Lake Albert, Uganda and experimental compatibility of local Biomphalaria spp. Parasitol Int. 2010;59:49-53.

21. Levitz S, Standley CJ, Adriko M, Kabatereine NB, Stothard JR. Environmental epidemiology of intestinal schistosomiasis and genetic diversity of Schistosoma mansoni infections in snails at Bugoigo village. Lake Albert Acta Trop. 2013;128:284-91

22. McCreesh N, Booth M. Challenges in predicting the effects of climate change on Schistosoma mansoni and Schistosoma haematobium transmission potential. Trends Parasitol. 2013;29:548-55.

23. Rowel C, Fred B, Betson M, Sousa-Figueiredo JC, Kabatereine NB, Stothard $J R$, et al. Environmental epidemiology of intestinal schistosomiasis in Uganda: population dynamics of Biomphalaria (Gastropoda: Planorbidae) in lake Albert and lake Victoria with observations on natural infections with digenetic trematodes. Biomed Res Int. 2015;2015:1-11.

24. Standley CJ, Goodacre SL, Wade CM, Stothard JR, Hoffman J, Webster J, et al. The population genetic structure of Biomphalaria choanomphala in Lake Victoria, East Africa: implications for schistosomiasis transmission. Parasit Vectors. 2014:7:524

25. Standley C, Vounatsou P, Gosoniu L, Jørgensen A. The distribution of Biomphalaria (Gastropoda: Planorbidae) in Lake Victoria with ecological and spatial predictions using Bayesian modelling. Hydrobiologia. 2012;683(1):249-64.

26. Standley CJ, Vounatsou P, Gosoniu L, Mckeon C, Adriko M, Kabatereine NB, et al. Micro-scale investigation of intestinal schistosomiasis transmission on Ngamba and Kimi islands, Lake Victoria, Uganda. Acta Trop. 2013;128:353-64.

27. Stensgaard A-S, Utzinger J, Vounatsou P, Hürlimann E, Schur N, Saarnak CFL, et al. Large-scale determinants of intestinal schistosomiasis and intermediate host snail distribution across Africa: does climate matter? Acta Trop. 2013:128:378-90.

28. Stothard JR, Sousa-Figuereido JC, Betson M, Adriko M, Arinaitwe M, Rowell $C$, et al. Schistosoma mansoni infections in young children: when are schistosome antigens in urine, eggs in stool and antibodies to eggs first detectable? Lyke KE, editor. PLoS Negl Trop Dis. 2011;5:e938.

29. Stothard JR, Stanton MC, Bustinduy AL, Sousa-Figueiredo JC, Van Dam GJ, Betson M, et al. Diagnostics for schistosomiasis in Africa and Arabia: a review of present options in control and future needs for elimination. Parasitology. 2014;141:1947-61.

30. Akinwale OP, Kane RA, Rollinson D, Stothard JR, Ajayi MB, Akande DO, et al. Molecular approaches to the identification of Bulinus species in south-west Nigeria and observations on natural snail infections with schistosomes. Helminthol. 2011;85:283-93.

31. Allan F, Dunn AM, Emery AM, Stothard JR, Johnston DA, Kane RA, et al. Use of sentinel snails for the detection of Schistosoma haematobium transmission on Zanzibar and observations on transmission patterns. Acta Trop. 2013;128:234-40

32. Kane RA, Stothard JR, Rollinson D, Leclipteux T, Evraerts J, Standley CJ, et al. Detection and quantification of schistosome DNA in freshwater snails using 
either fluorescent probes in real-time PCR or oligochromatographic dipstick assays targeting the ribosomal intergenic spacer. Acta Trop. 2013;128:241-9.

33. Brooker S, Hotez PJ, Bundy DAP. The global atlas of helminth infection: mapping the way forward in neglected tropical disease control. PLoS Negl Trop Dis. 2010;4:e779.

34. McCreesh N, Nikulin G, Booth M, Foster R, Appleton C, Pfluger W, et al. Predicting the effects of climate change on Schistosoma mansoni transmission in eastern Africa. Parasit Vectors. 2015;8:4.

35. Schur N, Hürlimann E, Stensgaard A-S, Chimfwembe K, Mushinge G, Simoonga C, et al. Spatially explicit Schistosoma infection risk in eastern Africa using Bayesian geostatistical modelling. Acta Trop. 2013;128:365-77.

36. Stensgaard A-S, Booth M, Nikulin G, McCreesh N. Combining process-based and correlative models improves predictions of climate change effects on Schistosoma mansoni transmission in eastern Africa. Geospat Health. 2016;11:406

37. Rubaihayo J, Ezekiel M, Philbert C, Andrew A, Kabateraine N, Brooker S, et al. Schistosomiasis transmission at high altitude crater lakes in Western Uganda. BMC Infect Dis. 2008:8:110.

38. Standley CJ, Adriko M, Besigye F, Kabatereine NB, Stothard RJ, Kabatereine $\mathrm{N}$, et al. Confirmed local endemicity and putative high transmission of Schistosoma mansoni in the Sesse Islands, Lake Victoria, Uganda. Parasit Vectors. 2011:4:29.

39. Quantum GIS Development Team. QGIS Geographic Information System. Open Source Geospatial Foundation Project [Internet]. 2016. Available from: www.qgis.org. Accessed 27th Jan 2017.

40. R Core Team. R: A Language and Environment for Statistical Computing Vienna: Statistical Programming Language $R ; 2016$.

41. NASA. Shuttle Radar Topography Mission [Internet]. 2016. Available from: http://www2.jpl.nasa.gov/srtm/. Accessed 27th Jan 2017.

42. Hosmer D, Hosmer T, Le Cessie S. A comparison of goodness-of-fit tests for the logistic regression model. Stat Med. 1997;16(9):965-80.

43. GAHI. Global Atlas of Helminth Infections [Internet]. Available from: http://www.thiswormyworld.org/. Accessed 27th Jan 2017.

44. Brooker S, Kabatereine NB, Smith JL, Mupfasoni D, Mwanje MT, Ndayishimiye O, et al. An updated atlas of human helminth infections: the example of East Africa. Int J Health Geogr. 2009;8:42.

45. Brooker S, Clements ACA. Spatial heterogeneity of parasite co-infection: Determinants and geostatistical prediction at regional scales. Int J Parasitol. 2009:39:591-7.

46. McCreesh N, Booth M, McCreesh N, Booth M, Kabatereine N, Brooker S, et al. The effect of simulating different intermediate host snail species on the link between water temperature and schistosomiasis risk. Munderloh UG, editor. PLoS One. 2014;9:e87892.

47. McCreesh N, Arinaitwe M, Arineitwe W, Tukahebwa EM, Booth M. Effect of water temperature and population density on the population dynamics of Schistosoma mansoni intermediate host snails. Parasit Vectors. 2014;7:503.

48. Schur N, Vounatsou P, Utzinger J. Determining treatment needs at different spatial scales using geostatistical model-based risk estimates of schistosomiasis. PLoS Negl Trop Dis. 2012;6:e1773.

49. Stothard JR, Sousa-Figueiredo JC, Navaratnam AM. Advocacy, policies and practicalities of preventive chemotherapy campaigns for African children with schistosomiasis. Expert Rev Anti Infect Ther. 2013;11:733-52.

50. Mandahl-Barth $\mathrm{M}$. The freshwater mollusks of Uganda and adjacent territories. Ann du Mus R du Congo Belge Tervuren. 1954;32:1-254.

51. Brown D. Freshwater snails of Africa and their medical importance. London: Taylor \& Francis; 1994.

52. Jorgensen A, Kristensen TK, Stothard JR. Phylogeny and biogeography of African Biomphalaria (Gastropoda: Planorbidae), with emphasis on endemic species of the great East African lakes. Zool J Linn Soc. 2007; 151:337-49.

53. Lachish T, Tandlich M, Grossman T, Schwartz E. High rate of schistosomiasis in travelers after a brief exposure to the high-altitude Nyinambuga crater lake, Uganda. Clin Infect Dis. 2013;57:1461-4.

54. Stothard JR, Campbell SJ, Osei-Atweneboana MY, Durant T, Stanton MC, Biritwum N-K, Rollinson D, Eloundou Ombede DR, Tchuem-Tchuenté L-A. Towards interruption of schistosomiasis transmission in sub-Saharan Africa: developing an appropriate environmental surveillance framework to guide and to support 'end game' interventions. IDoP. 2017;6(10). doi:10.1186/ s40249-016-0215-9.
55. Pleasant J. Intestinal schistosomiasis in mother and preschool child pairs along the shoreline of Lake Albert, Uganda: Diagnosis, distribution, risk factors and treatment. MSc Thesis. London: London School of Hygiene and Tropical Medicine; 2006.

56. King $\mathrm{CH}$, Hotez P, Alvarado M, Basanez M, Bolliger I, Bourne R, et al. It's time to dispel the myth of "asymptomatic" schistosomiasis. PLoS Negl Trop Dis. 2015;9:e0003504.

\section{Submit your next manuscript to BioMed Central and we will help you at every step:}

- We accept pre-submission inquiries

- Our selector tool helps you to find the most relevant journal

- We provide round the clock customer support

- Convenient online submission

- Thorough peer review

- Inclusion in PubMed and all major indexing services

- Maximum visibility for your research

Submit your manuscript at www.biomedcentral.com/submit
C Biomed Central 